\section{Motorcycle rider training}

Motorcycle riding is an accessible and cheap form of transport for many people worldwide, particularly in low and middle income countries where other forms of private transport are not affordable. Motorcycle riders, however, account for a relatively high proportion of road traffic-related fatalities and injuries in such countries. ${ }^{1}$

The lack of experience of many motorcycle riders has been cited as one potential cause of motorcycle crashes. ${ }^{2}$ Training of motorcycle riders has therefore been suggested as an important countermeasure for reducing both the number of crashes and the severity of injury. ${ }^{3}$ It is clear that riders need to learn how to ride a motorcycle but there is conflicting evidence about the right type of training.

In our recent Cochrane review published in 2010 we therefore sought to examine the effectiveness of motorcycle rider training. ${ }^{5}$ We aimed to quantify the effectiveness of pre and post-licence motorcycle rider training on the reduction of traffic offences, traffic crash involvement, injuries and deaths of motorcycle riders.

The review included 23 research studies, including three randomised trials, two non-randomised trials, 14 cohort studies and four case-control studies. The types of rider training that were evaluated varied in content and duration. Most studies suffered from serious methodological weaknesses, with most being non-randomised and controlling poorly for confounders. Small sample sizes and short follow-up times after training were also common.

Due to the poor quality of the studies identified, we were unable to draw any conclusions about the effectiveness of rider training on crash, injury, or offence rates. The findings suggest that mandatory pre-licence training may be an impediment to completing a motorcycle licensing process, possibly indirectly reducing crashes through a reduction in exposure. However, it is not clear if training (or what type) reduces the risk of crashes, injuries or offences in motorcyclists, and a best rider training practice can therefore not be recommended. As some type of rider training is likely to be necessary to teach motorcyclists to ride a motorcycle safely, rigorous research is needed.

The review highlighted the need for high quality studies examining the effectiveness of motorcycle rider training. The observational studies in the review were only able to control partly for confounding factors that may impact on outcomes, and the randomised trials had high dropout rates of riders after randomisation, resulting in significant selection bias. Given the lack of robust studies in this field, and the important need to address injury risk for motorcycle riders, it is crucial that studies in future are designed so as to avoid such issues.

Two major studies are currently underway and will add to the body of evidence on the topic in coming years. A longitudinal study, the Discovery project, from the Motorcycle Safety Foundation and the University of North Carolina Highway Safety Research Center, aims to determine the effects of involvement in a rider education and training system on crash prevention and avoidance skills, risk management, riding habits and safety characteristics. The VicRide trial is a randomised controlled trial underway in Australia involving over 2000 riders. Evaluated by researchers at the George Institute for Global Health and managed by VicRoads, this trial seeks to evaluate the effectiveness of an on-road coaching programme developed by Monash University Accident Research Centre in conjunction with Honda Australia Rider Training and Learning Systems Analysis.

For more information on the Cochrane Collaboration please visit http://www.cochrane.org/ or http://www.injuries. cochrane.org/, or email Emma Sydenham, Managing Editor of the Cochrane Injuries Group at emma.sydenham@lshtm.ac.uk. The Cochrane Collaboration offers training at centres worldwide for potential review authors-see the website for details.

\section{Rebecca Ivers}

Correspondence to Associate Professor Rebecca Ivers, The George Institute for Global Health, PO Box M201, Missenden Rd, NSW 2050 Australia;

rivers@georgeinstitute.org.au

Competing interests None.

Provenance and peer review Commissioned; not externally peer reviewed.

Published Online First 6 January 2011

Injury Prevention 2011;17:66. doi:10.1136/ip.2010.030940

\section{REFERENCES}

1. Mohan D. Road safety in less-motorized environments: future concerns. Int $J$ Epidemiol 2002;31:527-32.

2. Winn G. Two important trends in motorcycle safety regulations: rider education and conspicuity improvement. Detroit, MI, USA: Society of Automotive Engineers, 1987:147-52.

3. Vis AA. In-depth study of the hazards of motorcycling [De onveiligheid van motorrijden nader bekeken]. [Report no.: R-95-69]. Leidschendam, The Netherlands: SWOV Institute for Road Safety Research, 1995

4. Noordzij PC, Forke E, Brendicke R, et al. Integration of needs of moped and motorcycle riders into safety measures: review and statistical analysis in the framework of the European Research Project Promising. [Report no.: D-2001-5]. Leidschendam, The Netherlands: SWOV Institute for Road Safety Research, 2001.

5. Kardamanidis K, Martiniuk A, Ivers RO, et al. Motorcycle rider training for the prevention of road traffic crashes. Cochrane Database Syst Rev 2010;(10):CD005240. doi:10.1002/14651858. 